\title{
SEE AND BE SEEN Objects and subjects
}

\author{
Augusto Zubiaga \\ UPV/EHU \\ Facultad de Bellas Artes \\ Barrio Sarriena s/n, 48940 Leioa \\ augustopedro.zubiaga@ehu.eus
}

\author{
Lourdes Cilleruelo \\ UPV/EHU \\ Facultad de Educación \\ Barrio Sarriena s/n, 48940 Leioa \\ lourdes.cilleruelo@ehu.eus
}

\begin{abstract}
Electronic media can create a promising ecosystem. In the realm of this ecosystem a curious art focuses on playing by analogy, in an experimental way, to understand better the processes of individuation of the biological systems.
\end{abstract}

\begin{abstract}
Within this technological framework, this play visualizes how things work and function in the ecosystem. The play has already gone beyond the limits from which we are beginning to intuit the disturbing singularity of being observed in our own operating rules. Exteriority is expected from the processes of individuation of the physical objects. Exteriority is also being ambushed by an increasingly autonomous interiority, a complex withdrawal which already begins to emulate the way of being curious of the living beings, those who in turn are interested in, for better or worse, knowing us.
\end{abstract}

Objects and subjects. Neural networks. Processes and relationships. Resonance and sympathy.

\section{INTRODUCTION. THEORIES}

One might think that the normative space of technology (Broncano 2005) is constituted by two dimensions. One dimension is related to enhance human capabilities, and the other one is related to the true nature of technological achievements. These achievements have been the result of actions sought or, on the contrary, caused by chance and full of unintended consequences.

However, the attitudes can sometimes come to fruition, culminating in a species, or something that can be, in a certain way, classified as technological art. It is possible to perceive sometimes in a subtle way, sometimes in an obvious way, other tendencies, which are neither progressive nor intentional, nor the result of chance. It is about sympathies beyond foresight or luck, which can be sensitized, abandoned and yielded to the requirements of the objects that wish to arise.

In the play the object also becomes subject of the process of individuation: it wants to grow, adapt and evolve, and seems to look for necessary agents for its purpose. In this sense, it can be considered that the evolutionary approach is ontologically independent of the specific evolution of living organisms such as Crystallography, Chemistry... (Sheldrake 2011). Thus, individuation process of the object becomes the essential correlative of the flow of subject individuation, both entering a kind of resonance. It is not a new concept; this can be traced in the psychological basis on which the self-construction operations are articulated (Jung 2005), or in the peculiar alchemical conjunction between mind and matter.

Although it is half childlike, this contact mode between objects and subjects protected from a technological framework should not be understood as a regressive withdrawal (Joyce 2008), but rather as an ambush. This mode is taking some time to regain strength and try to make a new quantum leap towards a more complex orbit, towards a future in form of mystical or philosophical understanding.

Therefore, we are not placed only in the framework that is called artistic research, but also in the context of certain intimate impulses that involve psychic exchanges with objects (Harman 2015).

As mentioned above, the technologist feels driven in the search for the unknown through progress and discovery, and he will even face the unwanted. However, the agent and its object generate a 
reliable context of mutual attraction, that is the case, when we are aspirated by the unknown. At this moment a space for bricolage, which is defined by a certain emotional distance, is opened. This new context sets your mind free, and everything will be possible. Therefore, the activity and affectivity become the engines of an information process that will always be implicit and incomplete, but plausible.

It must be noted that this bricoleur's gesture emerges from the unconscious-unknown (LéviStrauss 1964), and for that reason, he/she lives in strangeness. The bricoleur operates from the blind spot, yet this is not allowed to become a source of reliable information. There is a contrast with the work of the technician, or even the artistic researcher (Borgdorff 2010). Their activities acquire meaning insofar as they are carrying out a relentless logic, even related to the epistemological evaluation of error (the impossible). In this way, they unveil the unknown or put order in the chaos; and then, make the unknown available as explicit information as well as argued, logical and repeatable practices, visible light.

In contrast, a dark mode of power is tending to emerge from the bricoleur. This is a black light that sometimes lights up privacy moments between objects and subjects. Encounters between dupes and bastards can be considered illegitimate and uncomfortable to witness by expert knowledge.

In fact, the bricoleur seems to be able to make things happen only if the task also implies the intimate relation of self-construction. In any case, it may come to exercise certain mode of probabilistic power. Insofar as he/she perhaps "may" feel empowered and able to do it from an amateur perspective. The bricoleur neither promises, nor takes nothing for granted or for sure, but perhaps it can be activated and encouraged to perform, in an unconscious movement which suddenly leads to a constructive choice.

In the same manner, the technician will put forward his knowledge not through a clearly represented diagram, but in a manner that comes across almost as a sleight-of-hand acquired by instinct and relegated to second nature as habit. His science will manifest itself at the level of the sensorial and the qualitative, very close to the concrete character of the material. This individual will be gifted with powers of intuitive collusion with the world which will give him a remarkable ability that will manifest itself, not in his conscience or in his discourse, but exclusively through his work. The artisan will be like a magician and his knowledge will be a working knowledge more than intellectual one, and it will be a capacity more than a knowledge. It will be secret to others because it is secret even to himself and to his own conscience on account of its nature. (Simondon 2015: 89)
The origin of the activation of these constructive choices is uncertain, but in any case they manifest themselves as an illusion to be made. This illusion is the fruit of consent, a call that simultaneously starts from the object and subject. There is a constant updating of the dialogue between the objects, which demand technical requirements (constructive choices). The subjects become increasingly evident interpreters and agents as an extent of the objects. In turn, this can be expected to lead to a permanent updating of a certain homeostatic balance in a metastable medium, repeating the scheme of operation of the technical device itself; past and future are aligned around this evolutionary singularity (Simondon 2009).

The See and Be Seen proposal must be understood from this perspective like going through this dynamic limit. It may be concluded that the flow of this proposal is permanently oriented and driven by a desire to be (Cilleruelo, Zubiaga and PeñaZabala 2015), and to let be loved. This piece is constantly evolving and adapting, leaving a trail of crystallised remains of past beings, subdued and shaped by the edges that delimit its exteriority.

In our opinion, this nuance defines a kind of universal techné close to what has been known as philosophiae naturalis, and close to reality according to the unfolded science and magical thought (Newton, Cardano...).

\section{PRACTICES}

According to this philosophical framework we have settled in favour of intuition and the free association of objects and concepts. The key underlying the technical process must be understood from the viewpoint of acceptance as the non-computability of the processes involved in the consciousness of the biological matrix (Godfrey-Smith 2017).

Andrew Smart (2018) sets out a number of premises regarding the possibility of designing conscious machines. His fundamental premises imply the consideration that artificial consciousness will not be computational, but will arise due to another non-biological, but physical process. Under this prism, code and computing become fuzzy or, at least, non-essential concepts which can be avoided.

Under these conditions, the See and Be Seen working progress has been created as an autonomous nervous system which generates own activity in a functional way. In addition, equipped with sensory organs, the art installation intertwines with its environment via electromechanical 
actuators, an interface consisting of optoelectronic neural networks, code (Computer Graphics) and connectivity.

For the moment, the art assembly is provided by a vision system and more than 100 analogue electronic units that emulate biological neuron activation function (Fig.1). Some of them are previously interconnected by layers or ganglia (the default-mode network); others, however, are directly available and therefore, can be modified. Consequently, we could play at interconnecting in different ways by means of optic fiber (Fig.2), trying to emulate biologically inspired complex patterns of functioning.

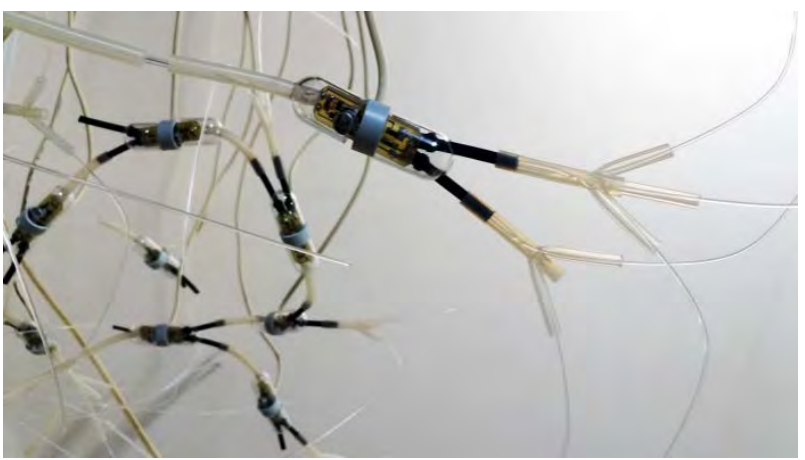

Figure 1: Neural Network. Each neuron consists of an axon, and excitatory and inhibitory synaptic capacity

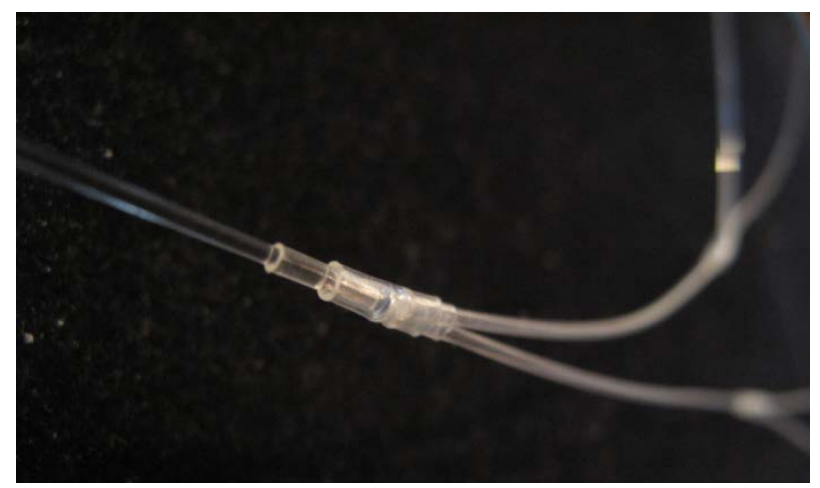

Figure 2: Dendrites consisting of optic fiber

Our neuron emulator circuit (Fig.3) has been materialized and reproduces a profound truth that affects, from its apparent simplicity, the intrinsic quality of the living.

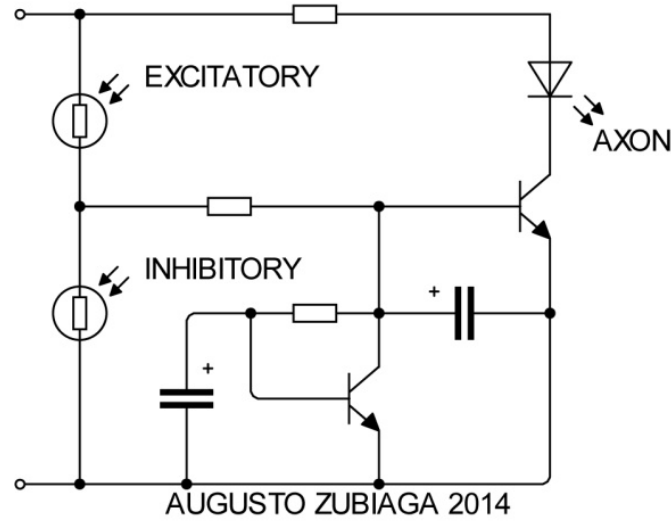

Figure 3: Augusto Zubiaga, Electronic neuron (2014)

In fact, in materialistic terms the underlying mechanism of the living can be understood as a material configuration which reaches a certain degree of provisional equilibrium related to the exterior characteristics. It is a state of metastability, as compromise between an internal force field and external one. In other words, these antagonistic poles have modified each other to constitute a balance, but these are the result of a momentary technical standoff. In this situation, the additive or subtractive incorporation of a force or signal determines the decentralization and consequent relaxation of the system. This happens in the form of a discharge of potential that in turn triggers changes or reflections in the exterior itself, for example generating resonances or intermittent cycles of relaxation. By reproducing this mechanism, we have managed to emulate the functioning of biological neurons to some extent.

Then, the basic principles underlying the functioning of neural networks have been applied for a vision organ implementation. The optical system (Fig.4, 5) is designed in a way that it has substantial anatomical elements of a biological organ, such as a lens, sensitive iris to luminosity variations, a retina, and an optic nerve which connects the surface of the retina to a network of neurons. 


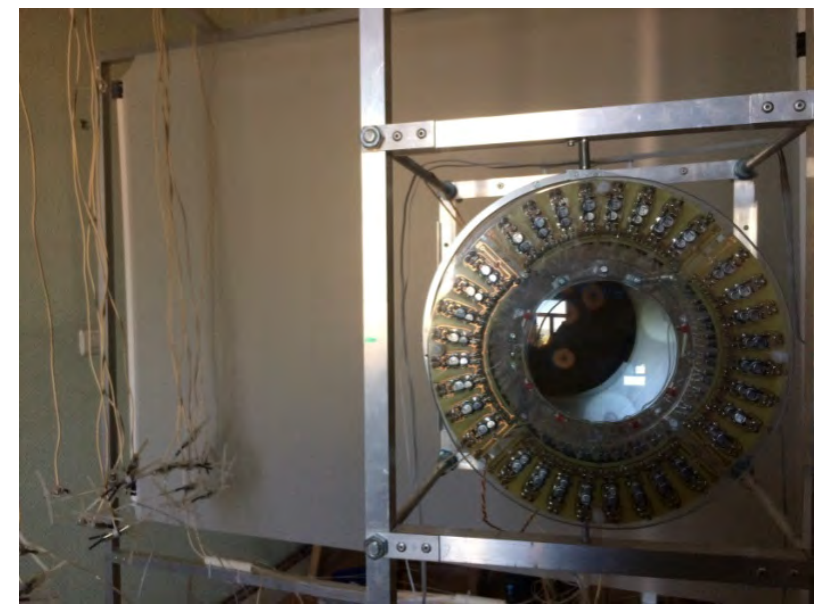

Figure 4: Organ of vision. By emulating biological systems, the 32 retinal receptors inhibit each other (Smith 1981), thus a constant pattern of basal activity is generated in form of background noise, which is modified by light variations in the environment that affect the artificial retina

The selective activation of neurons generates activity patterns which can be visualized through a real-time monitoring system developed by the Processing software (Fig. 7, 8). In addition, this environment of development builds an illusion sensitive to this selective activation. Indeed, a background is offered to the organ of vision which observes a self-generated world, its own world. It is possible as long as we do not somehow stand in the way, (physically or through electronic devices). We can generate interferences in intrusive ways in its vision field (Fig. 6) or in its own hallucinatory processes (Smart 2018).

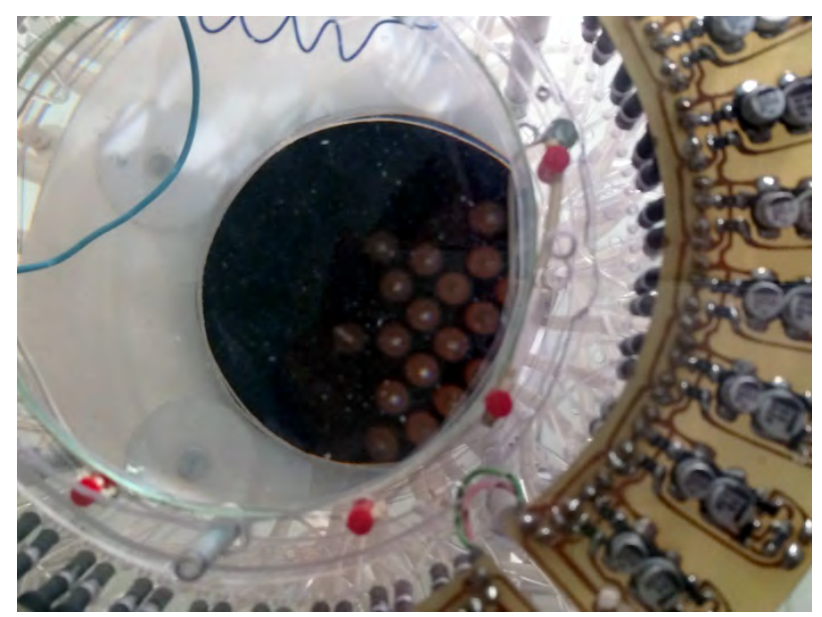

Figure 5: Detail of the retinal receptors. The converging lens focuses the scene on the fiber optic terminals of those receivers. In the periphery, the neuronal circuits, which receive the variations in luminosity, can be observed and converted into discrete luminous pulses.

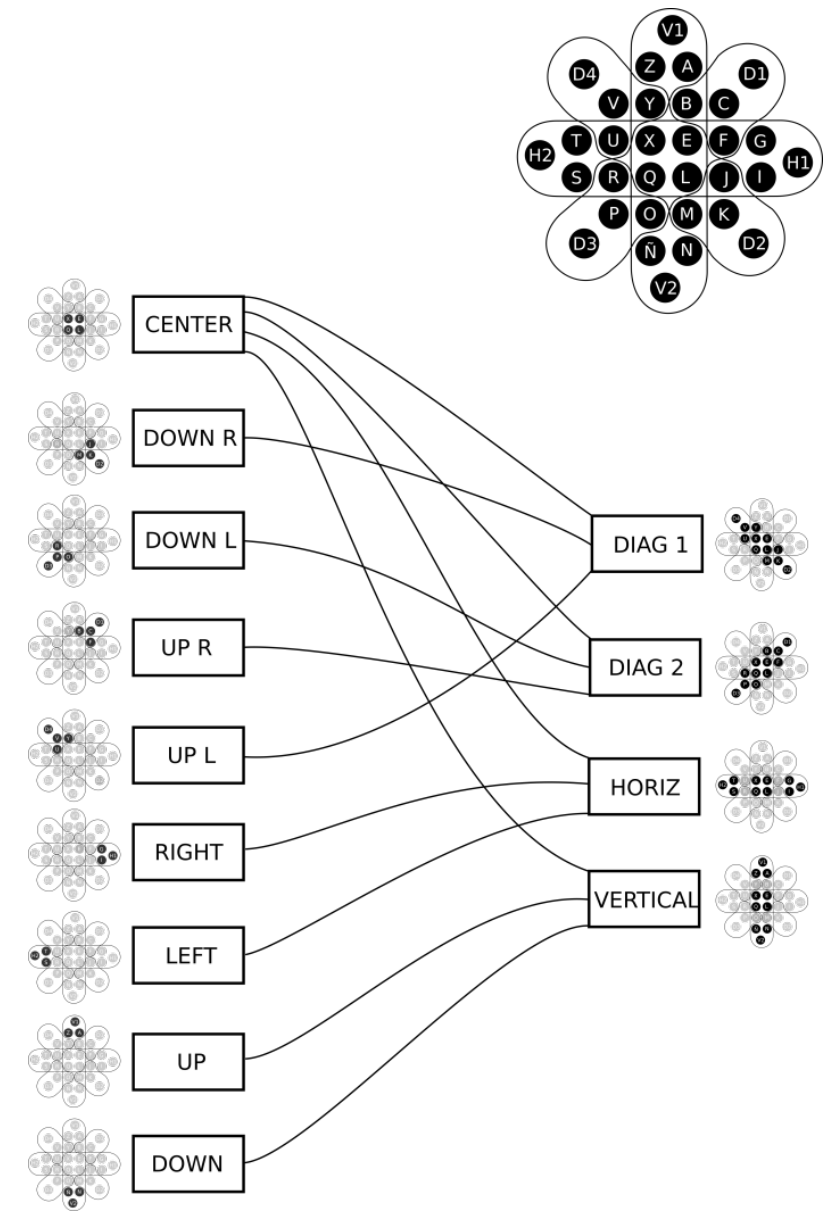

Figure 6: Retinal receptors grouped in independent selective beams, sensitive to horizontal, vertical and diagonal shapes (work in progress)

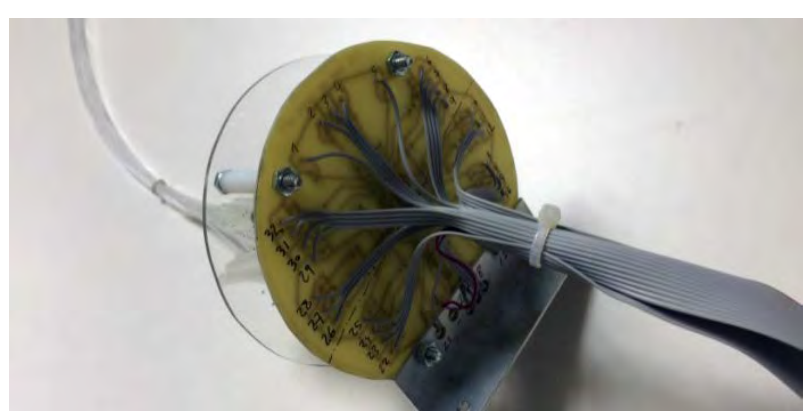

Figure 7: Optoelectronic interface. The luminosity variations from the activity of the 32 receptors are transmitted to the retina by the optic nerve. These variations are converted into electrical modulations and interpreted in the Arduino-Processing environment 


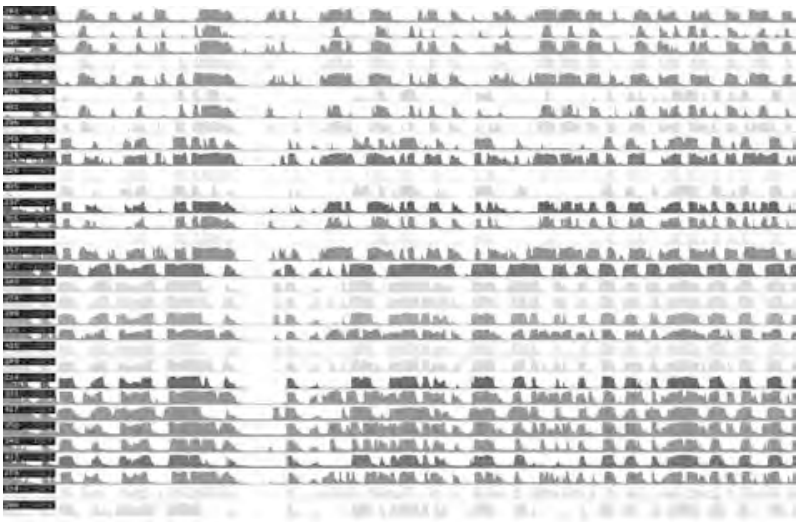

SEE AND BE SEEN 2016

Figure 8: Activity graph of the 32 retinal receptors by Processing

Not until we have developed an external intervention device in the activity of the defaultmode network, using a matrix of 4 programmable neurons with punched cards (Figs. 10, 11, 12, 13, 14 ), has been revealed the intrinsic complexity of biological systems. It is unsettling to think that the new variations, which would be induced, have not even added to the more than 4,000,000,000 combinatorial possibilities of this matrix. For example, there has been coupling in series or in parallel with other similar matrices, even with a reduced number of neurons, or even providing feedback with the default-mode network itself.

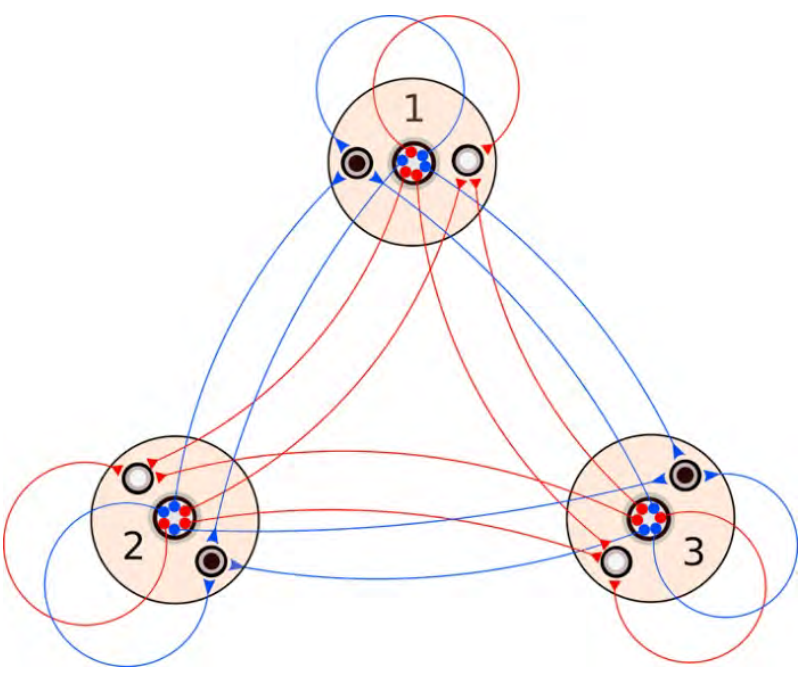

Figure 9: Connective diagram for 3 neurons. The red arrows represent excitatory synapses, and the blue ones inhibitory synapses. All possible connections are shown in the figure. We can reprogram the assembly by selectively pruning certain connections. In this device, the connectivity is verified by optical fiber and the light may be intercepted by means of opaque perforated cards

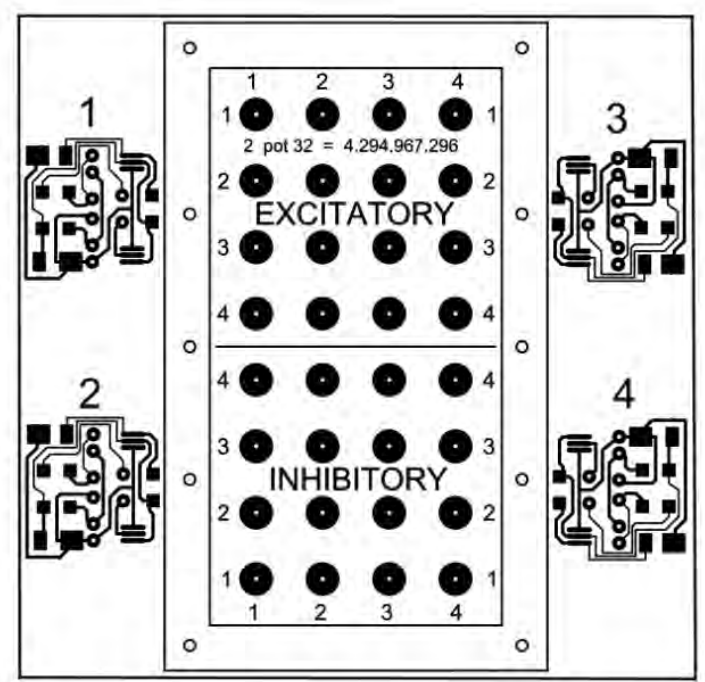

Figure 10: Matrix to test possible combinatorial of 1, 2, 3 and 4 neurons
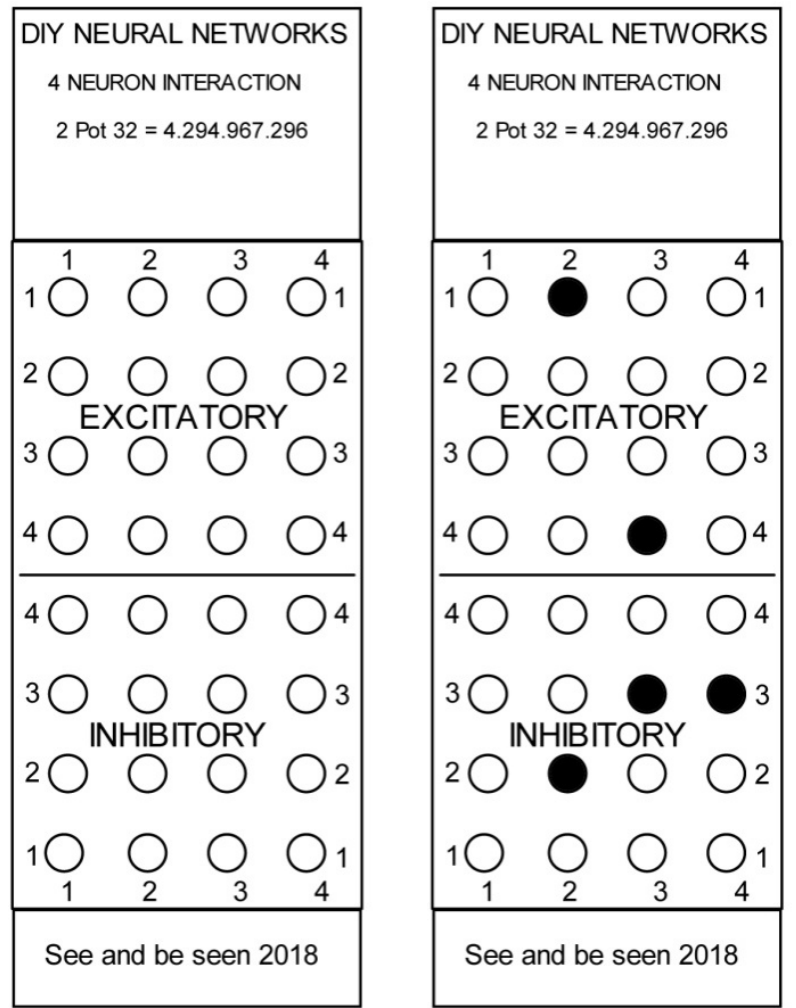

Figure 11: Punch card designed to program connective combinatorial up to 4 neurons. The card facilitates selective neural pruning. In the example, neuron 2 excites neuron 1 and also inhibits itself. Neuron 3 excites neuron 4 and inhibits neuron 3, and neuron 4 inhibits neuron 3 . The possible combinatorial is enormous $(4,294,967,296)$, and its results are unpredictable 


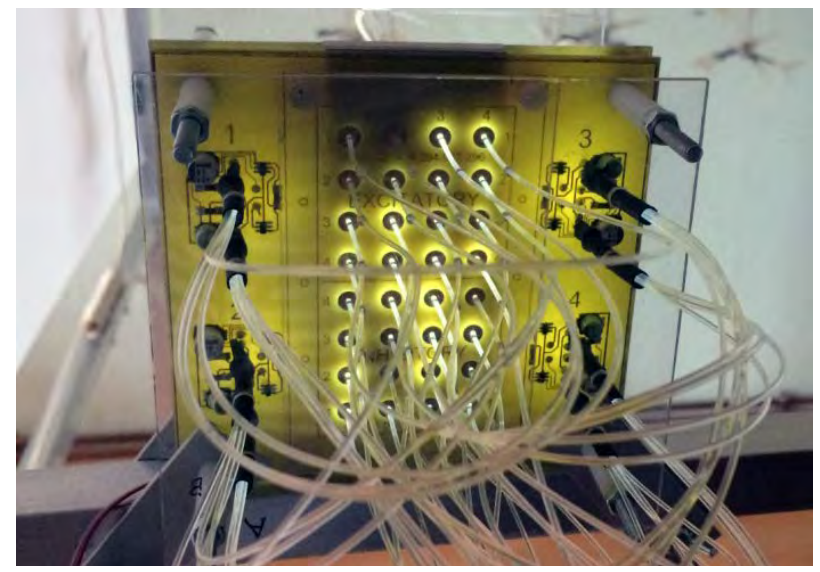

Figure 12: 4-neuron programming device. The connectivity can be modified by means of punch cards

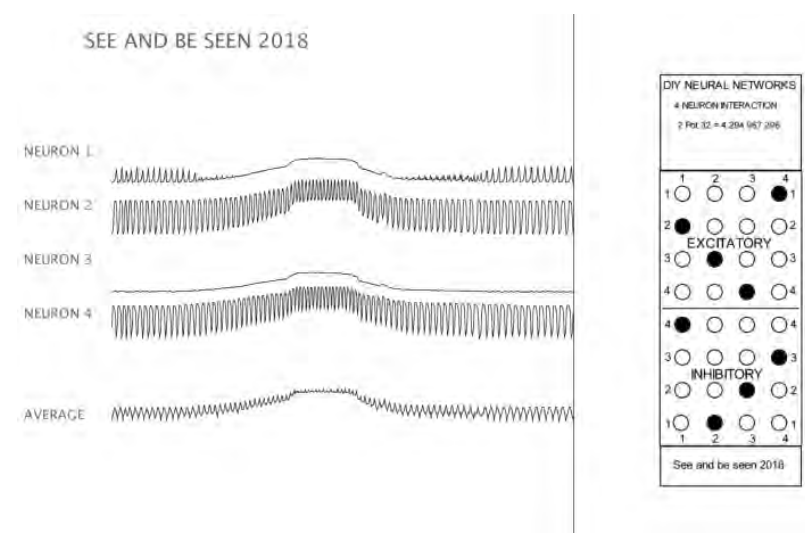

Figure 13: 4 active neurons. For the same connectivity configuration, changing patterns here are the result of intensity variations in the brightness of the surrounding environment

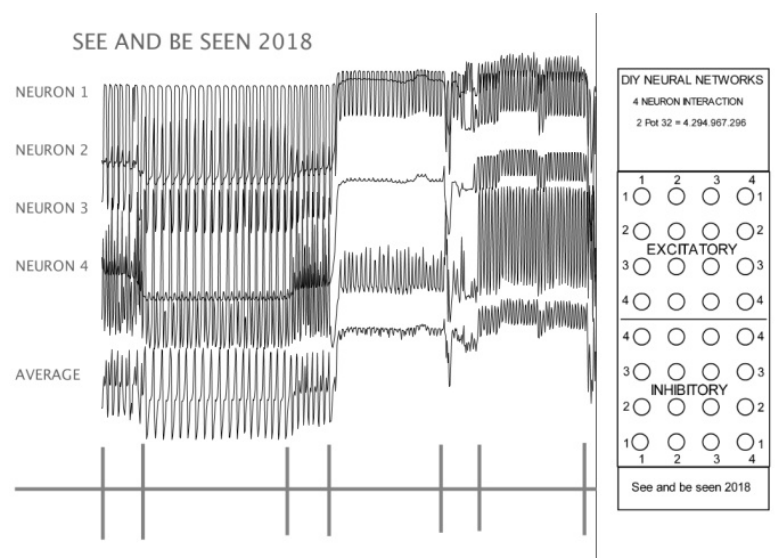

Figure 14: 4 active neurons. Here, changing patterns are the result of brightness variations and connectivity settings

\section{SYNCHRONICITIES}

In terms of performance, we have also found out that the system is extremely sensitive to exogenous and endogenous variations. Light and power are two variables that directly affect the computing mode. The bare optical fiber, which establishes the connection between neurons, is directly influenced by ambient light and flashes caused by the activity of nearby neurons (Fig. 13). This phenomenon induces unpredictable feedback which alters activity patterns and rates (Fig.14). Electrical current variations in the power supply also induce alterations in the activation patterns of neural networks. These intensity variations are not translated into mere slowdowns or loss of intensity of communication between neurons, but rather into the emergence of clearly differentiated activity patterns, which could be related by analogy with hallucinatory states caused by hypoxia, brain chemistry imbalances, etc.

On a different level, we have explored the possibility of establishing something like a systematic routine of the connective states that could be derived from the own structure of the neuronal units, with which we are working. This play is based on the constructive logic of neurons. Their connective qualities should reveal some analogies that could suggest links with deep reality structures. For example, we have observed that connectivity in sets of one, two, three, four or more neurons generates concrete numerical series that are curiously significant.

Starting from the structural imperative (Selverston 2010), a neuron consisting of an axon (output), an exciter input and an inhibitor input may be theoretically connected to itself according to 2 connecting links, self-exciting, or self-inhibiting. Nevertheless, when the action potential is extended to two neurons (Fig.15), the feeder links are increased to 8. Therefore, three neurons can be connected in 18 possible ways, four neurons in 32 ways, five in 50 , and so on.

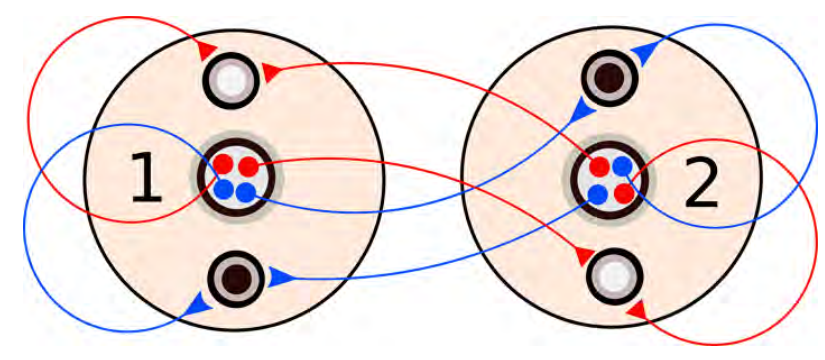

Figure 15: Action potential for two neurons amount to eight. Possible states, to 256 
In other words, 1 neuron represents 2 bits, 2 neurons can represent 8 bits, 3 neurons 18 bits and 4 neurons, 32 bits, and so on.

By assigning two states (0-1) to each pathway, the combinatorial capacity for a neuron can be configured according to 4 possible states. The power of two neurons can be manifested according to 256 modes. The combinatorial of three neurons can take 261,144 forms. Furthermore, the combinatorial variations for four neurons amount to $4,294,967,296$, or in other words, 32 bits. Thus, the combinatorial for 5 neurons is on cosmic magnitude: combinations.
$112,589,906,842,842,620$
We do not know under what kind of framework these hybrid realities (Latour 2012, Harman 2012) may make sense. Though beyond the symbolic logic, or the principle of causality, we can imagine that the reality is somehow reflected in the numerical. Even those model as simple as our device are far from revealing the true nature of their operation way. Indeed, it is virtually impossible to anticipate the threshold, activation mode, and characteristics of a given neural configuration. In despite of the fact that the simplest configurations are predictable and repeatable, in general, the system is too dependent on the external environment, and on its own internal resonances. This in itself is excellent news.

\section{LAST WARNING}

We would like to emphasise firmly to the readers that this text should not be understood as a scientific text. We are not scientists; we are moving in the terrain of aesthetic parameters in terms of our objectual developments, as well as the theoretical framework in which these have been contextualised.

That means that the epistemological framework has been replaced with an alternative one which could be closer to a possible epistemogony. Here, the criteria of objectivity required to a discourse of scientific matrix have been replaced by our radical contextualism, based on our ability to know and be interested in things as active individual subjects

We recognize that this point of view, in its apparent arbitrariness and lack of rigour, may be irritating to the expert connoisseur. By contrast, we declare ourselves bricoleurs, not only in terms of our practical proposals, but also in relation to our theoretical artifacts.

Here, the most important thing is not some idea of progress of knowledge, but a contextualised representational reflection, both materially and conceptually: mistakes, omissions, unknown terrae, chimeras and mythical spaces are permitted. We are referring to the origin and characteristics of our ability to be inspired, and also to our own ability to know and represent. In short, the idea that defines our activities is not much progress, but return (to the origins). 


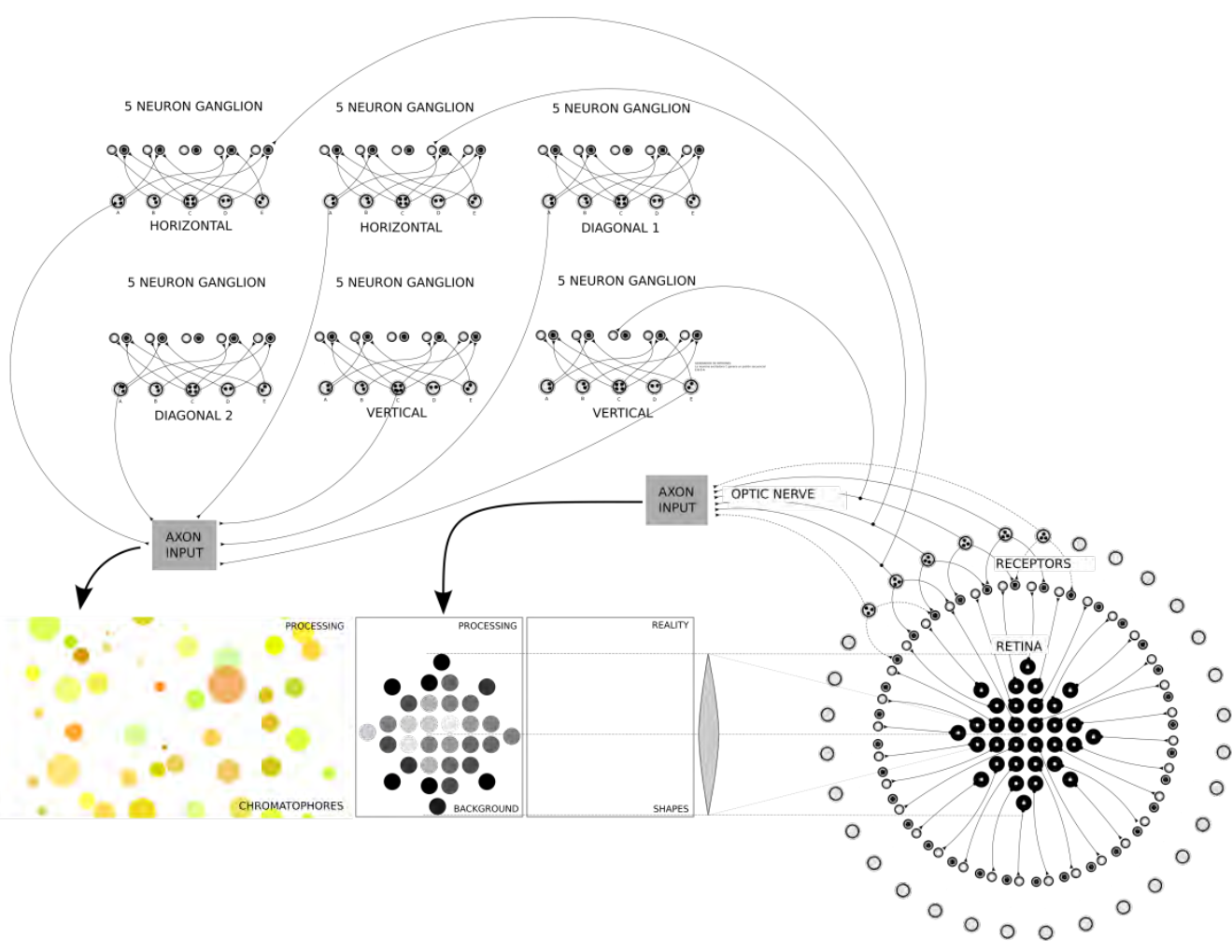

Figure 17: General outline of the See and Be Seen art installation

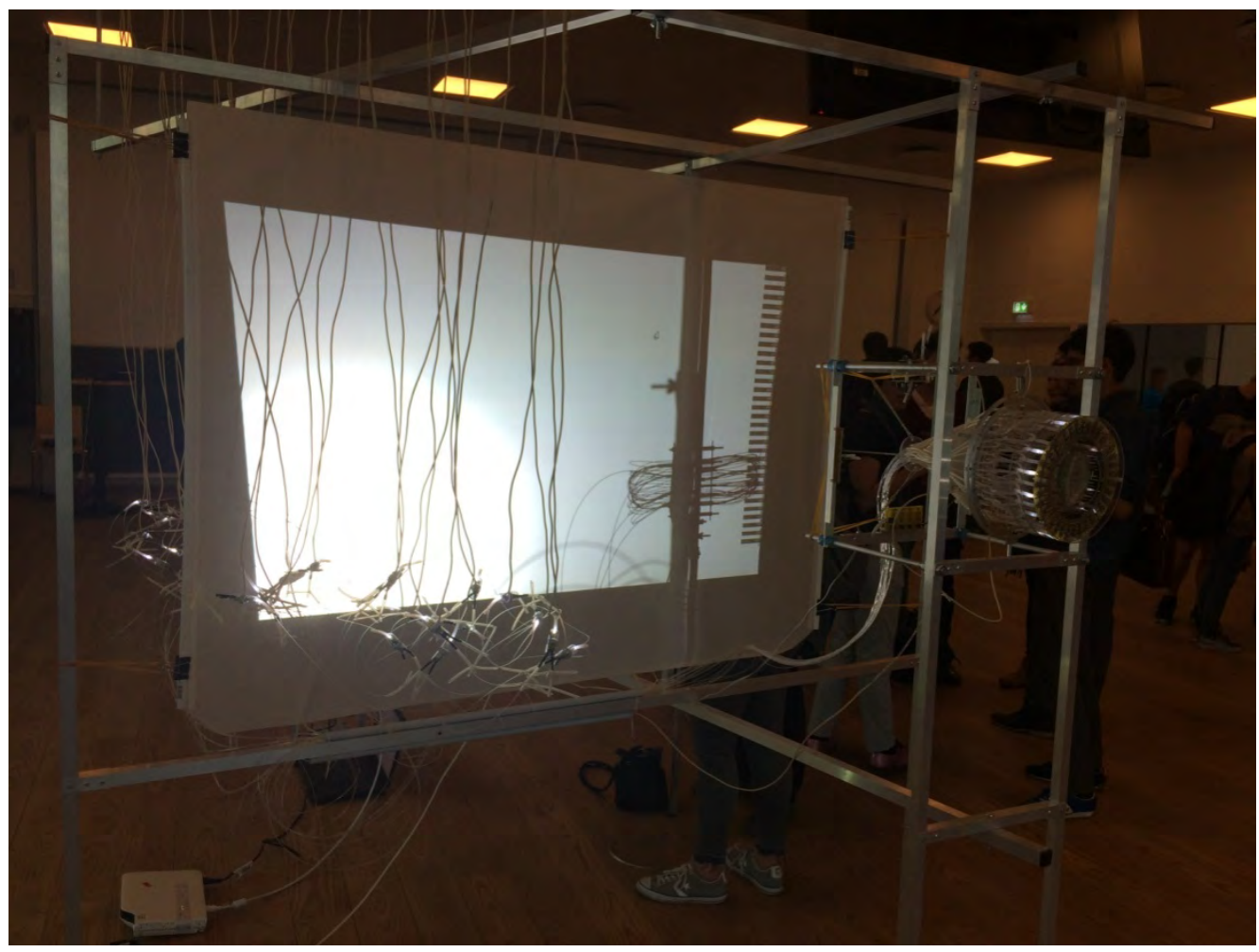

Figure 18: See and Be Seen, at Aalborg University, EVA-Copenhaguen, 2018 


\section{REFERENCES}

Borgdorff, H. (2010) El debate sobre la investigación en las artes. Cairon: revista de ciencias de la danza, 13, pp. 25-46.

Broncano, F. (2005) La agencia técnica. Revista Iberoamericana de Ciencia, Tecnología y Sociedad, 5 (2), pp. 95-107.

Cilleruelo, L., Zubiaga, A., and Peña-Zabala, M. (2015) Desired problems: An artistic approach in the field of neural networks. In Mateus-Berr, R. \& Götsch, M. (eds.) Perspectives on Art Education Conversations Across Cultures. De Gruyter, Berlin/Boston.

Godfrey-Smith, P. (2017) Otras Mentes. Taurus, Barcelona.

Harman, G. (2015) Hacia el Realismo Especulativo. Caja Negra, Buenos Aires.

Harman, G. (2012) On the supposed societies of chemicals, Atoms, and Stars. In Gabriel Tarde (ed.) Savage Objects. Godofredo Pereira, Guimarães.

Joyce, J. (2008). Retrato del Artista Adolescente. Alianza, Madrid.

Jung, C. (2005) Psicología y Alquimia. Trotta, Madrid.

Latour, B. (2012) Nunca fuimos Modernos. S.XXI, Buenos Aires.

Lévi-Strauss, C. (1964) El pensamiento salvaje. Fondo de cultura económica, México.

Selverston, A. I. (2010) Invertebrate central pattern generator circuits. Philosophical Translations of Royal Society B, 365, pp. 2329-2345. http://rstb.royalsocietypublishing.org/content/royptb/ 365/1551/2329.full.pdf (retrieved 5 June 2018)

Sheldrake, R. (2011) Una nueva ciencia de la vida. Kairós, Barcelona.

Simondon, G. (2015) On the Mode of Existence of the Technical Objects. http://topologicalmedialab.net/xinwei/classes/readin gs/Simondon/OnTheModeOfExistenceTechnicalOb jects/English/Part\%202/SimondonSecond\%20part \%20English2_080704.pdf (retrieved 5 May 2018)

Simondon, G. (2009) La individuación, a la luz de las nociones de forma e información. Cactus y La cebra, Buenos Aires.

Smart, A. (2018) Más Allá de ceros y unos. Clave Intelectual, Madrid.

Smith, C.U.M. (1981) El cerebro. Alianza Universidad, Madrid. 